\title{
Erythrocyte Anisocytosis as an Index of Severity in Acute Pancreatitis
}

\section{Okan Murat Aktürk, 담 Adnan Hut}

Department of General Surgery, University of Health Sciences, Istanbul Haseki Training and Research Hospital, Istanbul, Turkey

\begin{abstract}
Introduction: Most of the acute pancreatitis cases (AP) are mild; however, severe forms are risky for the patients, and those patients may benefit from early aggressive therapy. In this study, we investigated the predictivity of red cell distribution width (RDW) as a potential biomarker of severity.

Methods: In this study, a total of 123 patients with AP were classified high risk (Ranson score $\geq 3$ or more, HR) and low-risk patients (Ranson score $\leq 3$, LR). The patients were then investigated about the relationship of RDW to the severity of the disease and factors that affect prolonged hospital stay.

Results: The median age and stay were 56 (IQR 46-71) years and four (IQR 3-5) days. Elevated levels of RDW corresponded to HR patients compared with the LR patients, 13.90 (IQR 13.40-14.78) vs 13.40 (IQR 13.00-14.00), $p=0.001$, respectively. Prolonged hospital stay was related to higher Ranson scores and elevated lipase levels.

Discussion and Conclusion: High lipase levels at hospitalization may be associated with a prolonged hospital stay. Elevated RDW levels may help in the prediction of high risk in acute pancreatitis patients at hospital admission.

Keywords: Acute pancreatitis; Ranson score; red cell distribution width.
\end{abstract}

G allstones pose a significant health problem in Western societies, affecting approximately $10 \%$ to $15 \%$ of the adult population. Thus, approximately 20 to 25 million Americans suffer from the condition ${ }^{[1]}$. Gallstones are responsible for nearly $40 \%$ of pancreatitis cases ${ }^{[2]}$. Acute pancreatitis (AP) is one of the most common diseases of the gastrointestinal tract, with a rapid onset inflammatory process that varies in clinical outlook and severity, while the incidence is reported between 4.9 and 73.4 cases per 100.000 individuals around the world ${ }^{[3]}$. Although the disease is mild and associated with a good prognosis in most patients, $15 \%$ to $20 \%$ of the patients with AP may progress into a harder clinical course with higher morbidity and mortality rates ${ }^{[4]}$.
The Ranson criteria are some of the earliest predictive models and are widely used in clinical practice as a risk scoring system in acute pancreatitis ${ }^{[5]}$. Five parameters upon admission and six parameters after 48 hours of hospitalization are evaluated; however, a meta-analysis of 110 studies showed that this scoring system might have a high falsepositive rate ${ }^{[6]}$. Thus, there is still room for improvement in the prediction of severity in patients with AP.

Red blood cell distribution width (RDW) is the measure of the variability in the size of the circulating erythrocytes ${ }^{[7]}$. RDW is reported to be significantly associated with inflammatory markers like C-reactive protein and fibrinogen ${ }^{[8,9]}$. It was found to be an independent marker of short- and long-term prognosis in intensive care units ${ }^{[10]}$. Elevated 
RDW was found to be a negative prognostic marker in patients with chronical obstructive pulmonary disease ${ }^{[11]}$, osteosarcoma ${ }^{[12]}$, and coronary artery disease ${ }^{[13]}$, as well as has been used as both a diagnostic ${ }^{[14]}$ and prognostic ${ }^{[15]}$ marker for cancers.

In this study, the relationship between serum hematological parameters and the Ranson score in a group of early AP patients was investigated. We hypothesized that RDW increases with the severity of pancreatitis in line with the Ranson criteria. Secondary outcomes are the factors that cause prolonged hospital stay.

\section{Materials and Methods}

The diagnosis is based on the Revised Atlanta Criteria of 2012 (updated from 1992) with the demonstration of biliary stones or intrahepatic biliary enlargement ${ }^{[16]}$. Demographic, radiographic, and laboratory data were collected from patient records for the retrospective study. Ranson scores for each patient were calculated using data recorded 24 hours, and then, 48 hours after admission. Permission was given by the local ethics committee in full compliance with the Helsinki declaration, assigned with the number 18.04.2018/118. The study period was between November 2016 and February 2018 in the general surgery department of Istanbul Haseki Training and Research Hospital.

Statistical analyses were performed using SPSS software, IBM SPSS Statistics for Windows, Version 22.0, Armonk, NY. Normality of data distribution was assessed using the Shapiro-Wilk test. All values were expressed as median (interquartile range), mean \pm standard deviation, or count (percentage). Comparisons were made using a chi-square test or Fisher's exact test for categorical data, the MannWhitney U-test for continuous non-normally distributed variables, and the Kruskal Wallis analysis for comparison of multiple non-normally distributed variables for a particular parameter.

\section{Results}

The data were tested for normality using the Shapiro-Wilk test and found to be non-normally distributed, thus expressed accordingly as the median and interquartile range (IQR). Of the 123 patients included in this study, the median age was 56 (IQR 44-73). The majority of the patients were female (64\%). There was no mortality in the study group. Half of the patients (52\%) had a low Ranson score of 1-2 (Table 1). Only $14.6 \%$ of the patients had a score of $\geq 4$, and one patient $(0.8 \%)$ had a score of 5 . The patients were separated into two groups: low-risk (LR, Ranson score $<3$ ) and high risk (HR, Ranson score $\geq 3$ ). When high and low Ranson groups were compared concerning RDW, lipase, amylase CRP, hospital stay and age, the only significant difference was in the age and RDW parameters ( $p<0.01$ for both) (Table 2$)$. Then, hospital stay was analyzed in light of the parameters that cause prolonged in-stay. The hospital stay was found to be correlated with high Ranson scores and high lipase levels ( $p=0.001$ and $\mathrm{p}=0.006$, respectively) (Table 3 ).

Table 1. The descriptive statistics of the study group

\begin{tabular}{lcccc}
\hline & Median & $\begin{array}{c}\mathbf{2 5}^{\text {th }} \\
\text { percentile }\end{array}$ & $\begin{array}{c}\mathbf{5 0}^{\text {th }} \\
\text { percentile }\end{array}$ & $\begin{array}{c}\mathbf{7 5}^{\text {th }} \\
\text { percentile }\end{array}$ \\
\hline Age (years) & 56.00 & 46.00 & 56.00 & 71.00 \\
Glucose & 143.00 & 119.00 & 143.00 & 185.50 \\
AST & 220.00 & 115.00 & 220.00 & 483.00 \\
LDH & 370.50 & 261.30 & 370.50 & 539.50 \\
WBC & 11.01 & 8450.00 & 11.01 & 15.66 \\
Amylase & 1666.00 & 914.00 & 1666.00 & 2532.00 \\
Lipase & 3503.00 & 1356.00 & 3503.00 & 6450.00 \\
Hbg & 13.80 & 12.10 & 13.80 & 15.00 \\
MCV & 85.00 & 81.45 & 85.00 & 88.50 \\
CRP & 10.79 & 5000.00 & 10.79 & 30.57 \\
Stay & 4 & 3 & 4 & 5 \\
\hline
\end{tabular}

Age: in years; Glucose: $\mathrm{mg} / \mathrm{dL}$; AST (aspartate amino transferase) U/L; LDH (lactate dehydrogenase): U/L; WBC (white blood cell count): x109/L; Amylase: U/L; Lipase: U/L; Hbg, (hemoglobin): g/dL; MCV (mean corpuscular volume): fl; CRP (C-reactive protein): $\mathrm{mg} / \mathrm{L}$; Stay: days.

Table 2. Comparison of non-Ranson parameters, stay and age regarding high and low Ranson score groups

\begin{tabular}{lccc}
\hline & Low-risk (IQR) & High-risk (IQR) & P \\
\hline RDW & $13.40(13.00-14.00)$ & $13.90(13.40-14.78)$ & 0.001 \\
Amylase & $1628.00(891.50-2676.00)$ & $1712.00(931.50-2499.00)$ & 0.653 \\
Lipase & $3589.00(1648.00-6540.00)$ & $3924.00(1245.00-6332.00)$ & 0.369 \\
CRP & $10.19(5.00-14.55)$ & $14.10(5.15-41.75)$ & 0.085 \\
Stay & $3(3-4)$ & $3(3-5)$ & 0.071 \\
Age & $49(40-61)$ & $65(55-75)$ & 0.001 \\
\hline
\end{tabular}

Age: in years; Glucose: $\mathrm{mg} / \mathrm{dL} ; \mathrm{AST}$ (aspartate aminotransferase) U/L; LDH (lactate dehydrogenase); U/L; WBC (white blood cell count): x109/L; Amylase: U/L; Lipase: U/L; Hbg, (hemoglobin): g/dL; MCV (mean corpuscular volume): fl; CRP (C-reactive protein): $\mathrm{mg} / \mathrm{L}$; Stay: days; IQR: Interquartile range. 
Table 3. Analysis of risk factors for a prolonged hospital stay

\begin{tabular}{lc}
\hline Parameter & p \\
\hline Age (years) & 0.132 \\
High Ranson score & $<0.001^{*}$ \\
RDW (\%) & 0.815 \\
Amylase (U/L) & 0.058 \\
Lipase (U/L) & $0.006^{*}$ \\
\hline
\end{tabular}

\section{Discussion}

Although the mortality rate from AP is declining and now remains around $2 \%$, the incidence of the disease is rising worldwide ${ }^{[17]}$. The majority of patients heal without ramifications; however, $10-20 \%$ of the patients undergo a severe attack that may cause mortality, and this high-risk group of patients may benefit from intensive therapy ${ }^{[18]}$. The identification of these high-risk patients at the time of hospital admittance is important for reducing complications, and the mortality arising from the disease. Several severity scoring systems have been used in addition to the Ranson score: the Acute Physiology and Chronic Health Evaluation (APACHE)-II scores ${ }^{[19]}$ and the Balthazar Computed Tomography Severity Index ${ }^{[20]}$. Recently, many studies have been carried out about RDW and pancreatitis, in which RDW has been investigated to predict the prognosis for patients with severe AP.

Kılıç et al. ${ }^{[21]}$ studied the relationship between RDW and patients with severe AP using the Bedside Index for Severity in AP in a group of 343 patients. For patients with a Ranson score $\geq 4$, a cut-off value of (14\%) for RDW was defined by the receiving operator characteristics curve. Researchers found a significant difference regarding RDW levels between patients with mild and severe AP.

Zang et al. found that significantly higher RDW levels were observed in patients with moderately severe AP and severe AP when compared with patients suffering from mild AP $(14.03 \pm 1.74 \%$ vs. $13.23 \pm 1.23 \%)$. They identified a threshold for admission to the ICU, as patients with RDW $\geq 13.55 \%$ had a significantly higher ICU admission ratio than those with a smaller RDW value ${ }^{[22]}$.

RDW has also been studied in patients with severe AP, retrospectively, to see if the parameter has any discriminate properties about the survivors and non-survivors who had been admitted to the ICU ${ }^{[23]}$. RDW has been found to be significantly correlated with the APACHE II and SOFA scores and reportedly has better prognostic value for severe AP patients than both of these scores; thus, it could easily be used in clinical practice.
RDW has also been used in conjunction with other parameters to predict the mortality of patients with AP. In a retrospective cohort study of 102 patients, the RDWto-platelet ratio was assessed to predict in-hospital mortality for patients with AP. The researchers found that it was effective in predicting mortality in $80 \%$ of the patients $^{[24]}$. This prognosticator has also been shown to predict poor prognosis among patients diagnosed with breast cancer ${ }^{[25]}$.

In a study by Yalçın et al. ${ }^{[26]}$, they investigated the relationship of RDW to the severity of AP. In a group of 180 patients, they found that high RDW values on admission to the hospital were associated with severe disease, and at a cut-off level of 16.4, the RDW was able to predict the presence of acute necrotizing pancreatitis.

In a study of 406 patients, Zhou et al. ${ }^{[4]}$ investigated the predictivity of several biochemical and hematological parameters, as well as classification systems including Ranson and APACHE 2 scores. RDW was found to be superior to other laboratory predictors in predicting not only severe AP but also the mortality linked with AP. Among the laboratory parameters studied, RDW had the highest discriminatory capacity; thus, researchers proposed that RDW could be used in conjunction with present scoring systems for better predictivity.

As a secondary outcome, it has been reported that the severity of AP is independent of the elevation in serum amylase/lipase level upon hospital admission, and it can prove to be severe without significant elevation of lipase ${ }^{[27]}$. However, our data suggest that lipase levels must be checked, and if found high, the patients must be aggressively treated to avoid a prolonged hospital stay. Elevated lipase levels have been linked to severe prognosis in children with $\mathrm{AP}^{[28]}$.

There are some limitations to our study. Our sample size is moderate, and the majority of the AP patients are mild. Due to the retrospective nature of the study selection, bias is inevitable.

\section{Conclusion}

Our results indicate that the RDW level at admission was significantly different between patients with mild and severe AP based on the Ranson score. High lipase levels should also be monitored upon hospitalization because they may be associated with a prolonged hospital stay. RDW, which is easy to obtain and cheap to test, may be used as an auxiliary test to augment the prediction of high risk in AP patients upon hospital admission. 
Ethics Committee Approval: The Ethics Committee of Istanbul Haseki Training ve Research Hospital provided the ethics committee approval for this study (18.04.2018/118).

Peer-review: Externally peer-reviewed.

Authorship Contributions: Concept: O.M.A., A.H.; Design: O.M.A., A.H.; Data Collection or Processing: O.M.A., A.H.; Analysis or Interpretation: O.M.A., A.H.; Literature Search: O.M.A., A.H.; Writing: O.M.A.

Conflict of Interest: None declared.

Financial Disclosure: The authors declared that this study received no financial support.

\section{References}

1. Stinton LM, Shaffer EA. Epidemiology of gallbladder disease: cholelithiasis and cancer. Gut Liver 2012;6:172-87. [CrossRef]

2. Garber A, Frakes C, Arora Z, Chahal P. Mechanisms and Management of Acute Pancreatitis. Gastroenterol Res Prac. 2018;2018:6218798. [CrossRef]

3. Tenner S, Baillie J, DeWitt J, Vege SS; American College of Gastroenterology. American College of Gastroenterology guideline: management of acute pancreatitis. Am J Gastroenterol 2013;108:1400-15;1416.[CrossRef]

4. Zhou H, Mei X, He X, Lan T, Guo S. Severity stratification and prognostic prediction of patients with acute pancreatitis at early phase: A retrospective study. Medicine (Baltimore) 2019;98:e15275. [CrossRef]

5. Ranson JH, Rifkind KM, Roses DF, Fink SD, Eng K, Localio SA. Objective early identification of severe acute pancreatitis. Am J Gastroenterol 1974;61:443-51.

6. De Bernardinis M, Violi V, Roncoroni L, Boselli AS, Giunta A, Peracchia A. Discriminant power and information content of Ranson's prognostic signs in acute pancreatitis: a meta-analytic study. Crit Care Med 1999;27:2272-83. [CrossRef]

7. England JM, Down MC. Red-cell-volume distribution curves and the measurement of anisocytosis. Lancet 1974;1:701-3.

8. Fornal M, Wizner B, Cwynar M, Królczyk J, Kwater A, Korbut RA, et al. Association of red blood cell distribution width, inflammation markers and morphological as well as rheological erythrocyte parameters with target organ damage in hypertension. Clin Hemorheol Microcirc 2014;56:325-35. [CrossRef]

9. Hu ZD, Chen Y, Zhang L, Sun Y, Huang YL, Wang QQ, et al. Red blood cell distribution width is a potential index to assess the disease activity of systemic lupus erythematosus. Clin Chim Acta 2013;425:202-5. [CrossRef]

10. Hunziker S, Celi LA, Lee J, Howell MD. Red cell distribution width improves the simplified acute physiology score for risk prediction in unselected critically ill patients. Crit Care 2012;16:R89. [CrossRef]

11. Karampitsakos T, Dimakou K, Papaioannou O, Chrysikos S, Kaponi M, Bouros D, et al. The role of increased red cell distribution width as a negative prognostic marker in patients with COPD. Pulm Pharmacol Ther 2020;60:101877. [CrossRef]

12. Zheng J, Yuan X, Guo W. Relationship between red cell distribution width and prognosis of patients with osteosarcoma.
Biosci Rep 2019;39:BSR20192590. [CrossRef]

13. Nagula P, Karumuri S, Otikunta AN, Yerrabandi SRV. "Correlation of red blood cell distribution width with the severity of coronary artery disease-A single center study". Indian Heart J 2017;69:757-61. [CrossRef]

14. Aksoy EK, Kantarcı S, Torgutalp M, Akpınar MY, Sapmaz FP, Yalçın GŞ, et al. The importance of complete blood count parameters in the screening of gastric cancer. Prz Gastroenterol 2019;14:183-7. [CrossRef]

15. Shota S, Saito H, Kono Y, Murakami Y, Shishido Y, Miyatani K, et al. Prognostic Significance of Pre- and Post-operative Red-Cell Distribution Width in Patients with Gastric Cancer. J Gastrointest Surg 2019;10.1007/s11605-019-04392-w. [CrossRef]

16. Banks PA, Bollen TL, Dervenis C, Gooszen HG, Johnson CD, Sarr MG, et al; Acute Pancreatitis Classification Working Group. Classification of acute pancreatitis--2012: revision of the Atlanta classification and definitions by international consensus. Gut 2013;62:102-11. [CrossRef]

17. Gapp J, Chandra S. Acute Pancreatitis. In: StatPearls. Treasure Island (FL): StatPearls Publishing; 2019. Available from: https:// www.ncbi.nlm.nih.gov/books/NBK482468/.

18. Cho JH, Kim TN, Chung HH, Kim KH. Comparison of scoring systems in predicting the severity of acute pancreatitis. World J Gastroenterol 2015;21:2387-94. [CrossRef]

19. Larvin M, McMahon MJ. APACHE-II score for assessment and monitoring of acute pancreatitis. Lancet 1989;2:201-5. [CrossRef]

20. Balthazar EJ, Robinson DL, Megibow AJ, Ranson JH. Acute pancreatitis: value of CT in establishing prognosis. Radiology 1990;174:331-6. [CrossRef]

21. Kılıç MÖ, Çelik C, Yüksel C, Yıldız BD, Tez M. Correlation between Ranson score and red cell distribution width in acute pancreatitis. Ulus Travma Acil Cerrahi Derg 2017;23:112-6.

22. Zhang T, Liu H, Wang D, Zong P, Guo C, Wang F, et al. Predicting the Severity of Acute Pancreatitis With Red Cell Distribution Width at Early Admission Stage. Shock 2018;49:551-5. [CrossRef]

23. Zhang FX, Li ZL, Zhang ZD, Ma XC. Prognostic value of red blood cell distribution width for severe acute pancreatitis. World J Gastroenterol 2019;25:4739-48. [CrossRef]

24. Cetinkaya E, Senol K, Saylam B, Tez M. Red cell distribution width to platelet ratio: new and promising prognostic marker in acute pancreatitis. World J Gastroenterol 2014;20:14450-4.

25. Takeuchi $H$, Abe M, Takumi $Y$, Hashimoto T, Miyawaki $M$, Okamoto $\mathrm{T}$, et al. Elevated red cell distribution width to platelet count ratio predicts poor prognosis in patients with breast cancer. Sci Rep 2019;9:3033. [CrossRef]

26. Yalçın MS, Tas A, Kara B, Olmez S, Saritas B. New predictor of acute necrotizing pancreatitis: Red cell distribution width. Adv Clin Exp Med 2018;27:225-8. [CrossRef]

27. Lankisch PG, Burchard-Reckert S, Lehnick D. Underestimation of acute pancreatitis: patients with only a small increase in amylase/lipase levels can also have or develop severe acute pancreatitis. Gut 1999;44:542-4. [CrossRef]

28. Coffey MJ, Nightingale S, Ooi CY. Serum lipase as an early predictor of severity in pediatric acute pancreatitis. J Pediatr Gastroenterol Nutr 2013;56:602-8. [CrossRef] 